\title{
Reduced plasma high-density lipoprotein and increased platelet activity in arterial versus venous blood
}

\author{
Michael Aviram, Avi Viener and J. Gerald Brook
}

Lipid Research Unit, Rambam Medical Center and Faculty of Medicine, Technion-Israel Institute of Technology, Haifa, Israel

\begin{abstract}
Summary: Plasma lipid and lipoprotein pattern and platelet activity were studied in blood samples derived from veins and arteries of 10 healthy male subjects. A significant reduction in plasma high-density lipoprotein (HDL) cholesterol, triglyceride and protein levels, as well as in plasma apolipoprotein A-I, was found when lipoproteins were derived from arterial blood in comparison to venous blood. All other lipoproteins were not significantly changed. Platelet activity measured as plasma beta-thromboglobulin levels and as collagen-induced platelet aggregation and ${ }^{14} \mathrm{C}$-serotonin release in platelet-rich plasma was markedly elevated when platelets were derived from arterial blood. Since reduced plasma HDL concentration and platelet activation are known risk factors for atherosclerosis, our study may suggest a further explanation for the presence of atherosclerotic lesions in arteries but not in veins.
\end{abstract}

\section{Introduction}

Atherosclerosis is the result of degenerative disorders of the arteries, characterized by thickening of the arterial wall, when accumulation of lipids in smooth muscle cells and macrophages occurs.' The atherosclerotic plaque occurs in arteries, but not in veins, and this can be related to differences in blood pressure, $\mathrm{pH}$ and morphology. Plasma lipid and lipoprotein pattern is well related to the risk of coronary heart disease. ${ }^{2}$ Platelet function has been shown to be elevated in patients with accelerated atherosclerosis. ${ }^{3}$

In the present study we analysed plasma lipid and lipoprotein pattern as well as platelet function in blood obtained from the arteries and veins of healthy subjects. Our purpose was to find out whether possible differences among the above parameters could explain the presence of atherosclerosis in arteries but not in veins.

\section{Materials and methods}

Blood $(60 \mathrm{ml})$ was drawn at $0800 \mathrm{~h}$, after 14 hours of fasting, from the antecubital vein and then from the radial artery of 10 healthy males who had taken no medication for at least 3 weeks preceding the study. The blood was drawn into EDTA ( $1 \mathrm{mmol} / 1)$ for lipid analysis and into $3.8 \%$ sodium citrate $(\mathrm{vol} / \mathrm{vol}=9: 1)$

Correspondence: M. Aviram, D.Sc., Lipid Research Unit, Rambam Medical Center, P.O.B. 9602, Haifa 31096, Israel. Accepted: 22 September 1986 for platelet studies. Plasma and lipoprotein cholesterol and triglycerides ${ }^{4,5}$ were determined by enzymatic methods, and protein concentration by the Folin reagent. ${ }^{6}$ Plasma lipoproteins were separated by discontinuous density gradient ultracentrifugation. ${ }^{7}$ The density of $4 \mathrm{ml}$ of plasma was raised to $1.25 \mathrm{~kg} / \mathrm{l}$ with potassium bromide. Four millilitres of sodium chloride solution $(d=1.084 \mathrm{~kg} / \mathrm{l})$ were then carefully laid over the plasma sample, followed by $4 \mathrm{ml}$ of sodium chloride $(d=1.006 \mathrm{~kg} / \mathrm{l})$. Ultracentrifugation was performed in an SW-41 rotor in a Beckman L2$65 \mathrm{~B}$ preparative ultracentrifuge at $35,000 \times g$ for 48 hours at $4^{\circ} \mathrm{C}$. Lipoproteins were separated and analysed for purity by immunoelectrophoresis. Plasma apolipoproteins were determined by immunoelectrophoresis $^{8}$ and platelet aggregation and serotonin release induced by $1 \mu \mathrm{g} / \mathrm{ml}$ of collagen (Hormon Chemie, Munchen, FRG) was studied within 1 hour of sampling, in platelet-rich plasma (PRP) preparation adjusted to $300,000 / \mu \mathrm{l}$ with platelet-poor plasma, according to the method of Born' and Jerushalmy \& Zucker, ${ }^{10}$ respectively. Plasma beta-thromboglobulin was analysed by radioimmunoassay kit (Radiochemical Centre Amersham, Buckinghamshire, UK). Special precautions were used in taking the blood, using a polystyrene syringe fitted with a 20 gauge needle, without vein compression, in order to prevent platelet activation during sampling. For apolipoprotein analysis, rocket immunoelectrophoresis was performed, using dilutions of 1:150 and 1:1000 for anti-A-I and anti-B, respectively. Plasma 
was diluted 1:25 with barbital buffer. The antibodies were prepared from purified apolipoproteins, which were also used for standardization.

The Wilcoxon rank test was used for analysis of the data. Results are expressed as mean \pm standard deviation.

\section{Results}

Plasma chlosterol and triglycerides refers to the total levels present in all lipoprotein fractions (Table I). Plasma concentrations of cholesterol and triglyceride and very-low-density lipoprotein (VLDL), and lowdensity lipoprotein (LDL) cholesterol and triglyceride concentrations and plasma apolipoprotein B concentrations were not significantly different when derived from venous or arterial blood (Table I). However, plasma high-density lipoprotein (HDL) cholesterol, triglyceride and protein components as well as plasma apolipoprotein A-I levels were significantly reduced when derived from arterial blood in comparison to venous blood (Table I), with reduction of 11, 21, 18 and $15 \%$, respectively.

Platelet functions studied by three different parameters were significantly increased when derived from arterial blood in comparison to venous blood (Table II). Plasma beta-thromboglobulin, which is a measure of in vivo platelet activity (whereas collageninduced aggregation and release measure activity in vitro), increased by $40 \%$. Platelet aggregation and ${ }^{14} \mathrm{C}$ serotonin release in PRP, induced by collagen, were also enhanced when obtained from arterial blood, by 11 and $13 \%$, respectively. Plasma beta-thromboglobulin was found to correlate positively $(r=0.80)$ with collagen-induced aggregation.

\section{Discussion}

Our study demonstrated increased platelet activity and reduced plasma HDL levels in blood samples derived from the arteries in comparison to those derived from veins. These results are associated with increased risk for atherosclerosis and thus may explain the phenomenon of atherosclerotic plaque in arteries but not veins. Platelet activation is associated with increased risk for atherosclerosis, as demonstrated in hyperlipidaemic patients and in patients with coronary heart disease. ${ }^{3,11,12}$ HDL has been shown to be an independent risk factor for atherosclerosis, and decreased plasma HDL concentration has been found in patients with accelerated atherosclerosis. ${ }^{13,14}$ In the present study, both increased platelet activity and reduced plasma HDL level were found, thus favouring increased risk for atherosclerosis in blood preparations derived from arteries in comparison to blood 
Table II Plasma $\beta$-thromboglobulin and platelet aggregation and ${ }^{14} \mathrm{C}$-serotonin release in PRP derived from venous and arterial blood

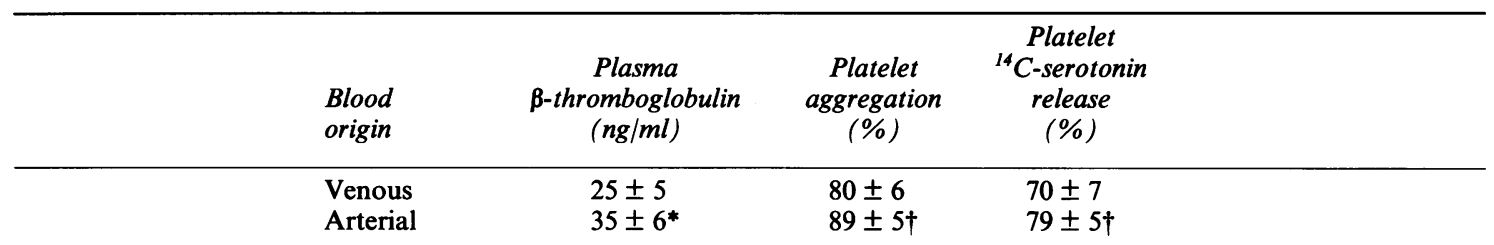

Platelet aggregation (amplitude) and ${ }^{14} \mathrm{C}$-serotonin release were determined in response to $1 \mu \mathrm{g} / \mathrm{ml}$ collagen in PRP. Results represent mean $(n=7) \pm$ s.d. Statistically significant differences between venous and arterial blood are shown by: ${ }^{*} P<0.01 ; \uparrow P<0.05$.

derived from a vein. Increased platelet activity in arteries may result from increased shear stress in comparison to the venous blood. The increased $\mathrm{pH}$ level as well as elevated $\mathrm{PO}_{2}$ in arterial blood can also contribute to increased platelet functions observed in PRP derived from arteries. Since plasma lipoproteins also affect platelet function ${ }^{15,16}$ and HDL has been shown to cause reduction in platelet activity in vitro, ${ }^{17,18}$ it might be that the reduced plasma HDL concentration in arteries is also responsible for the enhanced platelet activity. In fact, in several studies in humans, an inverse relationship between HDL levels and platelet function has been demonstrated. ${ }^{19,20}$

We can only speculate about the lower plasma HDL concentration found in arterial versus venous blood,

\section{References}

1. Ross, R. \& Glomset, J.A. The pathogenesis of atherosclerosis. N Engl J Med 1976, 295: 369-377.

2. Steinberg, D. Lipoproteins and atherosclerosis: A look back and a look ahead. Arteriosclerosis 1983, 3: 283-302.

3. Weksler, B.B. \& Nachman, R.L. Platelets and atherosclerosis. Am J Med 1981, 71: 331-323.

4. Zak, B. Cholesterol methodologies: A review. Clin Chem 1977, 23: 1201-1214.

5. Ziegenhorn, J. An improved method for enzymatic determination of serum triglyceride. Clin Chem 1975, 21: 1627-1629.

6. Lowry, O.H., Rosebrough, N.J., Farr, A.L. \& Randall, R.J. Protein measurement with the Folin phenol reagent. J Biol Chem 1951, 193: 265-275.

7. Aviram, M. Plasma lipoprotein separation by discontinuous density gradient ultracentrifugation in hyperlipoproteinaemic patients. Biochem Med 1983, 30: 111118.

8. Alaupovic, D., Curry, M. \& McConathy, W.J. In Carlson, L.A. (ed) International Conference on Atherosclerosis. Raven Press, New York, 1978, p. 109.

9. Born, G.V.R. Aggregation of blood platelets by aden- and we may suggest increased HDL binding to the arterial wall; thus, plasma HDL would be reduced in comparison to the venous wall.

Our study thus demonstrates increased risk for atherosclerosis in arteries. The reduced HDL levels can be related to impaired cholesterol-removal ability from the peripheral cells to the liver, and increased platelet activity can be associated with enhanced thrombotic tendency which is related to blood platelets found in arteries.

\section{Acknowledgements}

We thank Mrs Mira Rosenblat and Mrs Gertrude Dankner for technical assistance and Miss Ruth Singer for typing the manuscript. osine diphosphate and its reversal. Nature (London) 1969, 194: 927-930.

10. Jerushalmy, Z. \& Zucker, M.B. Some effects of fibrinogen degradation products (FDP) on blood platelets. Thromb Diath Haemorrh 1966, 15: 413-418.

11. Carvalho, A.C.A., Coleman, R.W. \& Lees, R.S. Platelet function in hyperlipoproteinaemia. N Engl J Med 1974, 290: 434-437.

12. Colman, R.W. Platelet function in hyperbetolipoproteinemia. Thromb Haemost 1978, 39: 284-293.

13. Lewis, B. Lipids. In Brown, S.S., Mitchell, F.L. and Young, D.S. (eds) Chemical Diagnosis of Disease. Elsevier/North Holland Biomedical Press, New York, 1979, p. 281.

14. Viener, A., Aviram, M. \& Brook, J.G. Abnormal plasma lipoprotein composition in hypercholesterolaemic patients induces platelet activation. Eur J Clin Invest 1984, 14: 207-213.

15. Brook, M., Winterstein, G. \& Aviram, M. Platelet function and lipoprotein levels after plasma exhange in patients with familial hypercholesterolaemia. Clin Sci 1983, 64: 637-642.

16. Aviram, M.\& Brook, J.G. Characterization of the effect 
of plasma lipoprotein on platelet function in vitro. Haemostasis 1983, 13: 344-350.

17. Aviram, M. \& Brook, J.G. The effect of blood constituents on platelet function: Role of blood cells and plasma lipoproteins. Artery 1983, 11: 297-305.

18. Aviram, M. \& Brook, J.G. Selective release from platelet granules by plasma lipoproteins. Biochem Med 1984, 32: 30-33.
19. Baruch, Y., Brook, J.G., Eidelman, S. \& Aviram, $M$ Increased high-density lipoprotein in plasma and dę creased platelet aggregation in primary biliary cirrhosis.. Atherosclerosis 1984, 53: 151-162.

20. Bierenbaum, M.L., Fleischman, A.I., Stier, A. et at? Increased platelet aggregation and decreased high-der sity lipoprotein cholesterol in women on oral contracep $\overline{\underline{D}}$ tives. Am J Obstet Gynecol 1979, 134: 638-641. 